\title{
Grouping species for predicting mixed tropical forest dynamics: looking for a strategy
}

\author{
Sylvie Gourlet-FleurY ${ }^{\mathrm{a} *}$, Lilian BLANC ${ }^{\mathrm{b}}$, Nicolas PICARD ${ }^{\mathrm{a}}$, Plinio SiST $^{\mathrm{c}}$, Jan DiCK ${ }^{\mathrm{d}}$, Robert NASI ${ }^{\mathrm{e}}$, \\ Mike D. SWAINE ${ }^{\mathrm{f}}$, Eric FORNI ${ }^{\mathrm{a}}$

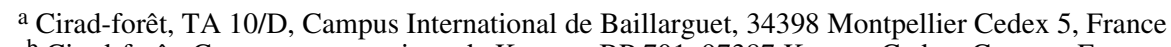 \\ ${ }^{\mathrm{b}}$ Cirad-forêt, Campus agronomique de Kourou, BP 701, 97387 Kourou Cedex, Guyane, France \\ ${ }^{c}$ EMBRAPA Amazonia Oriental/Cirad-forêt, Travessa Eneas Pinheiro, Belem PA 66095-100, Brazil \\ ${ }^{\mathrm{d}}$ Center for Ecology and Hydrology, Bush Estate, Penicuik, Midlothian, EH26 0QB, Scotland, United Kingdom \\ ${ }^{\text {e }}$ Cirad-forêt/CIFOR, TA 10/D, Campus International de Baillarguet, 34398 Montpellier Cedex 5, France \\ $\mathrm{f}$ Aberdeen University, School of Biological Sciences, Aberdeen AB24 3UU, United Kingdom
}

(Received 3 November 2004; accepted 15 April 2005)

\begin{abstract}
The high species diversity of mixed tropical forests hinders the development of forest dynamic models. A solution commonly adopted is to cluster species in groups. There are various methods for grouping species that can be linked to three strategies (i) the ecological subjective strategy, (ii) the ecological data-driven strategy, and (iii) the dynamic process strategy. In the first two strategies a species will be assigned to a single group while in the latter strategy, a specific grouping is defined for each process of population dynamics (typically based on recruitment, growth, mortality). Little congruency or convergence is observed in the literature between any two classifications of species. This may be explained by the independence between the sets of tree characters used to build species groups, or by the intra-specific variability of these characters. We therefore recommend the dynamic process strategy as the most convenient strategy for building groups of species.
\end{abstract}

cross-comparisons / functional groups / modelling strategy / species classifications

Résumé - Grouper les espèces pour prédire la dynamique des forêts tropicales humides : à la recherche d'une stratégie. Le développement de modèles de dynamique forestière adaptés aux forêts tropicales humides est compliqué par la très grande diversité spécifique caractérisant ces forêts. Les modélisateurs ont souvent eu recours, pour simplifier le problème, à des techniques de regroupement d'espèces. Il existe des méthodes diverses de regroupement, qui relèvent de trois grands types de stratégie : (i) stratégie écologique subjective, (ii) stratégie écologique basée sur l'analyse de données, (iii) stratégie des processus de dynamique populationnelle. Dans le cadre des deux premières stratégies, une espèce est affectée à un groupe et un seul alors que dans le cadre de la troisième, des groupes d'espèces sont définis pour chacun des processus de dynamique (recrutement, croissance, mortalité) pris séparément, et chaque espèce est affectée à trois groupes. Dans la littérature, on trouve peu d'exemples de congruence ou de convergence entre les groupes définis par ces différentes méthodes. Ceci peut être expliqué par l'indépendance existant entre les caractères utilisés pour fabriquer tel ou tel groupe, ou encore par la grande variabilité intraspécifique de ces caractères. Nous argumentons et concluons sur le fait que le recours à la stratégie des processus de dynamique paraît être la meilleure pour construire des groupes d'espèces adaptés à la prédiction de la dynamique des forêts tropicales.

comparaisons croisées / groupes fonctionnels / stratégie de modélisation / classifications d'espèces

\section{INTRODUCTION}

Understanding and predicting the dynamics of mixed tropical forests is difficult because, principally, of their high species diversity. This difficulty hinders the development of predictive dynamic models, essential for forest managers to simulate logging scenarios for sustainable exploitation. Models of forest dynamics require species specific parameters (such as growth rate, mortality rate, etc.), and the issue is to get a value of the parameters for each species. If a species is represented by a low number of individuals in the dataset that is used for model fitting (which is generally the case due to the high species diversity), then estimates of model parameters for this species will have a high variance, and even be unreliable. One solution to reduce this variance is to allocate the large number of tree species to a smaller number of groups, thus increasing the size of the sample used for parameter estimation. As far as modelling is concerned, species grouping is justified if the decrease in

\footnotetext{
* Corresponding author: sylvie.gourlet-fleury@cirad.fr
} 
parameter variance brings a gain in model prediction accuracy. Species grouping may also reveal important features of the ecosystem function [67].

Hereafter, we shall take for granted that species grouping is justified for the modelling of tropical forest dynamics, and shall focus on the methods for grouping species. Besides the clustering technique itself, grouping species raises questions such as: (i) How to assign rare species with unreliable parameters or even missing data? (ii) How to extrapolate a species classification on a well documented forest to another forest with scarce data? These two questions are not the focus of this paper.

Ideally, modellers look for functional groups sensu [29], i.e. "a non-phylogenetic classification leading to a grouping of organisms that respond in a similar way to a syndrome of environmental factors" with the further restriction that "response is mediated through the same mechanism", which differentiates mere "response groups" from real "functional groups". According to these authors, this double constraint should ensure that the groups will behave homogeneously under a large range of perturbations, giving the classification a greater extrapolative power. They suggest that the existence of functional groups implies that (i) there is an underlying "inherent structure" of species, and (ii) each functional classification reveals this structure. This inherent structure may thus be revealed by an overlap of classifications obtained from different character data sets (congruency) or for different purposes (convergence).

In reality, little evidence of congruency, and even less of convergence between classifications has been demonstrated so far. This can either mean that the inherent structure does not exist, that the characters selected to group species are not adequate, or that the analytical techniques used to group species are not appropriate [29].

The classifying techniques used by modellers for tropical forests have largely been driven by earlier works in forest ecology and dynamics, going back to the early 20th century [7, 69]. This strategy favours an ecological interpretation of the groups. On the other hand, one may choose to favour the accuracy of model predictions. Grouping species then simplifies to a combinatorial optimization problem to achieve the best agreement between observations and predictions [56]. The techniques used by modellers generally lie in between these two opposite points of view, and try to make a trade-off between ecological interpretation of the groups and accuracy of model predictions $[11,23,25,38,62]$. Numerous methods have been used, but they generally lack consistency and objectivity [23, 40], a caveat indeed not limited to trees and tropical forests [45]. It is therefore difficult to compare between forests and between models, and to ensure the extrapolative ability of the models built. Some authors have tried to compare classifications [1, 23, $30,33,70-72$ ] but like [29], failed to show evidence of real functional groups.

The objective of this paper is to select a clustering strategy to group species for the modelling of tropical forest dynamics aiming at efficiently predicting forest recovery after disturbance without hindering ecological interpretations. This selection is based on a review of the main methods used by ecologists and modellers to build species classifications for tropical rainforests taking advantage of the reasons why those previous classifications lacked congruency. We will focus on groups built to address tree population and community dynamics, rather than forest ecosystem functioning. Our paper describes first the main methods for grouping species, distinguishing between three strategies. The key concept that we shall call "dynamic process groups" is introduced at the end of this section. Second, some properties of the tree characters used for grouping species are presented, insofar as they explain the lack of congruency between classifications. The third section is devoted to the analysis of congruency between classifications. In the last section, the "dynamic process" strategy is selected as the most convenient and this choice is argued in the light of the previous discussion.

\section{MAIN STRATEGIES OF SPECIES CLASSIFICATION}

We can distinguish between three major types of tree species classifications, depending on the characters and methods used by the reviewed authors: (i) ecological subjective groups, (ii) ecological data-driven groups and (iii) dynamic process groups (corresponding to the components of forest dynamics: recruitment, growth, mortality).

\subsection{Ecological subjective groups}

Ecological subjective groups are based on characters that are relatively easy to measure over short periods of time or well documented in herbaria [67], mainly physiological and morphological traits. The decision to split the characters into different categories relies on empirical knowledge from field observation. This strategy, which assumes that groups exist and can be defined inductively, was qualified as "subjective" by [29].

A classical example is the pioneer/non-pioneer dichotomy [67], largely based on a single criterion: a requirement for full light for both germination and establishment. The pioneer group proved to be associated with a whole syndrome of characters [9, 67, 68], in contrast with the highly heterogeneous non-pioneer group. The pioneer/non-pioneer dichotomy was refined with other characters such as height at maturity or maximum height $[12,35,36,49,65,67]$, and wood density [40].

\subsection{Ecological data-driven groups}

Ecological data-driven groups are based either: (i) on dynamic characters (diameter increment, mortality rate, recruitment rate: data usually available for trees greater than $10 \mathrm{~cm} \mathrm{dbh}$ ), derived from successive measurements in permanent sample plots $[3,16,25,54]$; (ii) on morphological characters (e.g. maximum height) $[15,19,43,52,53]$; or, more often, (iii) on a combination of both. To build groups, multivariate analyses (mainly principal component analysis and cluster analysis) are applied to the data sets [1, 2, 6, 23, 24, 27, 42, 55] (see Tab. I). This strategy was qualified as "data-driven" or "data-defined" by $[29,30]$. Some authors further use the commercial/non commercial status of the species in order to obtain groups or subgroups meaningful for forest managers [2, 10, 42]. Others use wood density as a proxy of diameter increment, and combine 
Table I. Examples of species classifications into "ecological data-driven groups" for modelling purposes. Variables used are often population dynamic variables, but also morphological variables.

\begin{tabular}{|c|c|c|c|}
\hline Ref. & Variables used & $\begin{array}{c}\text { Number of } \\
\text { species analysed }\end{array}$ & $\begin{array}{l}\text { Number of groups } \\
\text { obtained }\end{array}$ \\
\hline [1] & Mean diameter increment, diameter of the largest tree & 256 & 16 \\
\hline$[2]$ & $\begin{array}{l}\text { Commercial/non commercial category, diameter increments, annual mortality rate, } \\
\text { proportion of dominant trees, largest diameter }\end{array}$ & 486 & 54 \\
\hline$[6]$ & Diameter increments & 112 & 7 \\
\hline$[23,24]$ & $\begin{array}{l}\text { Mean diameter in undisturbed stands, mean diameter increment per diameter class } \\
\text { (disturbed and undisturbed plots), recruitment rate (disturbed and undisturbed plots) }\end{array}$ & $\begin{array}{l}123 \text { (out of } 200 \text { in the } \\
\text { data bank) }\end{array}$ & 5 \\
\hline$[27]^{\mathrm{a}}$ & $\begin{array}{l}\text { First quartile, median and third quartile of the diameter increment distribution. Height } \\
\text { classes then used to further subdivise }\end{array}$ & 106 & 17 \\
\hline$[42]$ & $\begin{array}{l}\text { Mean diameter (undisturbed plots), mean diameter increment (logged }+ \text { thinned plots), } \\
\text { mortality rate (undisturbed plots), recruitment rate (undisturbed plots) }\end{array}$ & $\begin{array}{l}72 \text { (out of } 260 \text { in the } \\
\text { data bank) }\end{array}$ & $7^{b}$ \\
\hline$[51]$ & Commercial/non commercial category, wood density & 468 & 7 \\
\hline [55] & Predicted growth variable, recruitment variable & $\begin{array}{l}136 \text { (out of } 575 \text { in the } \\
\text { data bank) }\end{array}$ & 10 \\
\hline
\end{tabular}

a Those authors did not build dynamics models, but the philosophy of their grouping is very coherent with the other works cited here.

${ }^{b}$ Five ecological groups, crossed with 5 commercial categories, leading to 14 potential groups. Only 7 were kept, as large enough to allow parameter estimation of a matrix model.

Table II. Example of species classifications into growth groups. The groups depend on the formulation of a growth model.

\begin{tabular}{|c|c|c|c|}
\hline Ref. & Model used & $\begin{array}{c}\text { Number } \\
\text { of species analysed }\end{array}$ & $\begin{array}{c}\text { Number of groups } \\
\text { obtained }\end{array}$ \\
\hline$[31,33]$ & 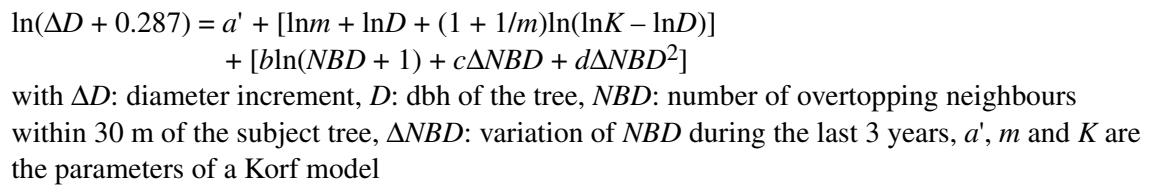 & 173 & 15 \\
\hline [47] & $\begin{array}{l}D I=\beta_{1}+\beta_{2} D \\
D I=\beta_{1}+\beta_{2} D+\beta_{3} D^{2} \\
\ln D I=\beta_{1}+\beta_{2} \ln D \\
\ln D I=\beta_{1}+\beta_{2} D+\beta_{3} \ln D \\
\text { with } D I \text { : diameter increment, } D: \text { dbh of the tree }\end{array}$ & 12 & 5 \\
\hline [51] & $\begin{array}{l}\ln b a i=\beta_{1}+\beta_{2} \ln b a+\beta_{3} b a+\beta_{4} S Q+\beta_{5} \ln B A+\beta_{6} O T B A \\
\text { with bai: individual basal area increment, } b a \text { : basal area of the tree, } S Q \text { : site quality (dummy } \\
\text { variable), } B A \text { : stand basal area, OTBA: overtopping basal area }\end{array}$ & 436 & 20 \\
\hline [57] & $\begin{array}{l}a_{t}=\alpha_{0}-\alpha_{1}\left(B_{t} / B_{0}\right)+\varepsilon_{t} \\
\text { with } a_{t} \text { mean diameter increment between } t \text { and } t+2, B_{t}: \text { basal area of the plot at } t, B_{0} \text { : initial } \\
\text { basal area of the plot, } \varepsilon_{t}: \text { residual. The variance-covariance matrix of the } \varepsilon_{t} \text { is modelled by } \\
\operatorname{Cov}\left(\varepsilon_{t}, \varepsilon_{t^{\prime}}\right)=\sigma^{2} \rho^{\left|t-t^{\prime}\right|} \text { to manage with data issued from successive remeasurements }\end{array}$ & 202 & 5 \\
\hline [70] & $\begin{array}{l}\ln (D I+\alpha)=\beta_{1}+\beta_{2} D+\beta_{3} \ln D+\beta_{4} S Q \ln D+\beta_{5} \ln B A+\beta_{6} O B A \\
\text { with } D I \text { : diameter increment, } D \text { : dbh of the tree, } S Q \text { : site quality, } B A \text { : stand basal area, } O B A \text { : } \\
\text { overtopping basal area }\end{array}$ & 237 & 41 \\
\hline
\end{tabular}

it either with morphological characters [40] or with commercial status to group their species $[51,73]$.

\subsection{Dynamic process groups}

Dynamic process groups are based primarily on one category of dynamic characters only: growth groups are based on diameter increments, mortality groups are based on mortality rates, and recruitment groups are based on recruitment rates. The method used to build the groups relies on a theoretical model considered to describe the selected process. Examples are given in Table II for growth and in Table III for mortality and recruitment. For each process, the parameters of the model are estimated by fitting the theoretical curve to the measured 
Table III. Example of species classifications into mortality and recruitment groups. The groups depend on the formulation of mortality and recruitment models.

\begin{tabular}{|c|c|c|c|}
\hline Ref. & Model used & $\begin{array}{l}\text { Number } \\
\text { of species } \\
\text { analysed }\end{array}$ & $\begin{array}{l}\text { Number } \\
\text { of groups } \\
\text { obtained }\end{array}$ \\
\hline & Mortality & & \\
\hline \multirow[t]{2}{*}{ [71] } & $\begin{array}{l}P=\left\{1+\exp \left[-\left(\beta_{0}+\beta_{1} \ln D B H+\beta_{2} D B H+\beta_{3} R S^{2}+\beta_{4} S Q+\beta_{5} B A+\beta_{6} \ln B A\right)\right]\right\}^{-1} \\
\text { with } P: \text { probability of dying, } D B H: \text { dbh of the tree, } R S: \text { relative status of the tree (overtopping basal area } \\
\text { divided by the total plot basal area), } S Q: \text { site quality, } B A: \text { stand basal area }\end{array}$ & 100 & 10 \\
\hline & Recruitment ( $\geq 10 \mathrm{~cm} \mathrm{dbh)}$ & & \\
\hline$[57]$ & $\begin{array}{l}r_{t}=\beta_{0}-\beta_{1}\left(B_{t} / B_{0}\right)+\varepsilon_{t} \\
\text { with } r_{t} \text { : recruitment between } t \text { and } t+2, B_{t} \text { : basal area of the plot at } t, B_{0} \text { : initial basal area of the plot, } \varepsilon_{t} \text { : } \\
\text { residual. The variance-covariance matrix of the } \varepsilon_{t} \text { is modelled by } \operatorname{Cov}\left(\varepsilon_{t}, \varepsilon_{t^{\prime}}\right)=\sigma^{2} \rho^{\left|t-t^{\prime}\right|} \text {, to manage with } \\
\text { data issued from successive remeasurements }\end{array}$ & 202 & 5 \\
\hline \multirow[t]{3}{*}{ [72] } & Recruitment is described through a two-stage approach & & \\
\hline & $\begin{array}{l}P=\left\{1+\exp \left[-\left(\beta_{0}+\beta_{1} P R E S+\beta_{2} B A+\beta_{3} \ln B A+\beta_{4} S O I L+\beta_{5} T R\right)\right]\right\}^{-1} \\
\text { with } P \text { : probability of recruitment, PRES: binary variable indicating the presence }(1) \text { or absence }(0) \text { of the } \\
\text { species in the stand, } B A \text { : basal area of the stand, SOIL: binary variable }(1: \text { soils derived from basic volcanic } \\
\text { and coarse granite parent materials, } 0 \text { : others), TR: treatment response }\left(\operatorname{Tr}=t e^{t / 9}\right) \text {, maximum } 9 \text { years after } \\
\text { treatment }\end{array}$ & 100 & 5 \\
\hline & $\begin{array}{l}\ln N=\beta_{0}+\beta_{1} \ln B A+\beta_{2} \ln (R N O+0.2)+\beta_{3} S Q+\beta_{4} S O I L \\
\text { with } N: \text { number of recruits }\left(\mathrm{ha}^{-1} \text { year }{ }^{-1}\right) \text {, RNO: relative importance of the species in the stand, } B A, S Q \text { and } \\
\text { SOIL as previously defined }\end{array}$ & 100 & 8 \\
\hline
\end{tabular}

data. Groups of species are then built to ensure the best similarity between the species specific theoretical curves within a group. The similarity between curves may be assessed in several ways, as the variance of the residuals of the fitting of the theoretical curve to data [70, 72], or as the Euclidean distance between the parameters of the curves [47, 57], or as a functional norm of the difference between curves [56], etc. Figure 1 illustrates on a theoretical example these different indices of similarity between two species. The building up of the species groups using these similarity indices may be done in various ways: cluster analysis [57], numerical optimization of a cost function [56], ad hoc sequential method [70], etc.

The theoretical model, once chosen, remains generally fixed. However an alternative method consists of modifying the theoretical model in an iterative way, as groups of species are formed: species with the same range of residuals are grouped together, a better adapted theoretical model is chosen for each group, and new residuals are examined and so on, until no species effect is left in the residuals $[31,33]$.

Researchers that use ecological subjective groups most often do not have modelling as their primary purpose, or they face a lack of dynamic data to correctly assign each species to a group. When the objective is to build predictive models of forest dynamics, and enough data are available from permanent sample plots, ecological data-driven groups using dynamic characters, and groups of dynamic process are usually preferred.

The philosophy underlying ecological groups on the one hand, and dynamic process groups on the other hand, is completely different. In the first case, researchers forming ecological groups assume that species behave homogeneously inside each group, particularly with respect to all the dynamic components (Fig. 2): they are real "response groups" and possibly

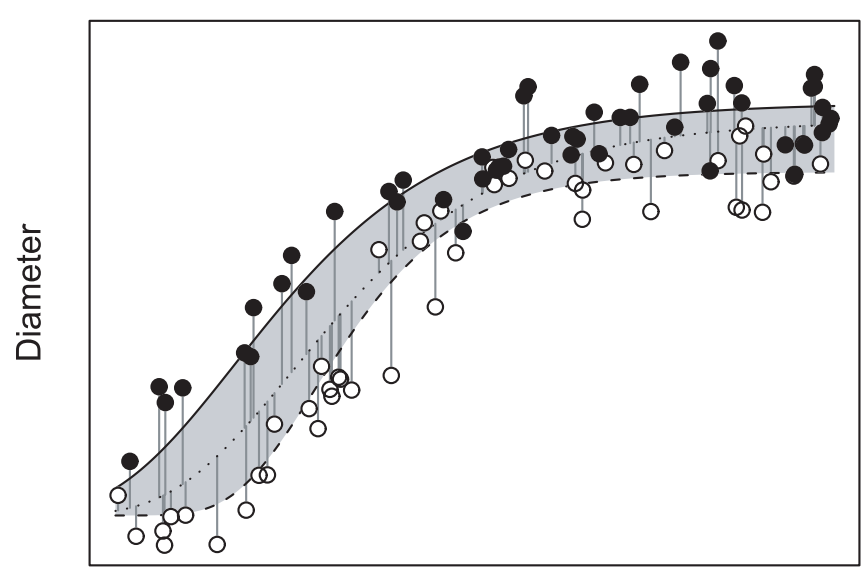

Time

Figure 1. Illustration of the different ways of assessing the similarity between curves fitted to data. This theoretical example shows diameter growth curves (the same could be done for mortality or recruitment using models given in Tab. III) and uses the Gompertz model as the growth model (see Tab. II for more realistic models): circles correspond to (fictitious) data and lines are fitted Gompertz curves. Black circles correspond to a species with the fitted Gompertz curve in solid line, and white circles correspond to another species with the fitted Gompertz curve in dashed line. The dotted line is the Gompertz curve fitted to all dots (black or white). The similarity between the two species growth curves can be assessed as the variance of the residuals of the Gompertz model in dotted line (shown as vertical segments), as a functional norm of the difference between the curve in solid line and the curve in dashed line (the surface of the area shown in grey corresponds, for example, to the $\mathrm{L}_{1}$ norm), or as a distance between the parameters of the Gompertz equations for the two species. 


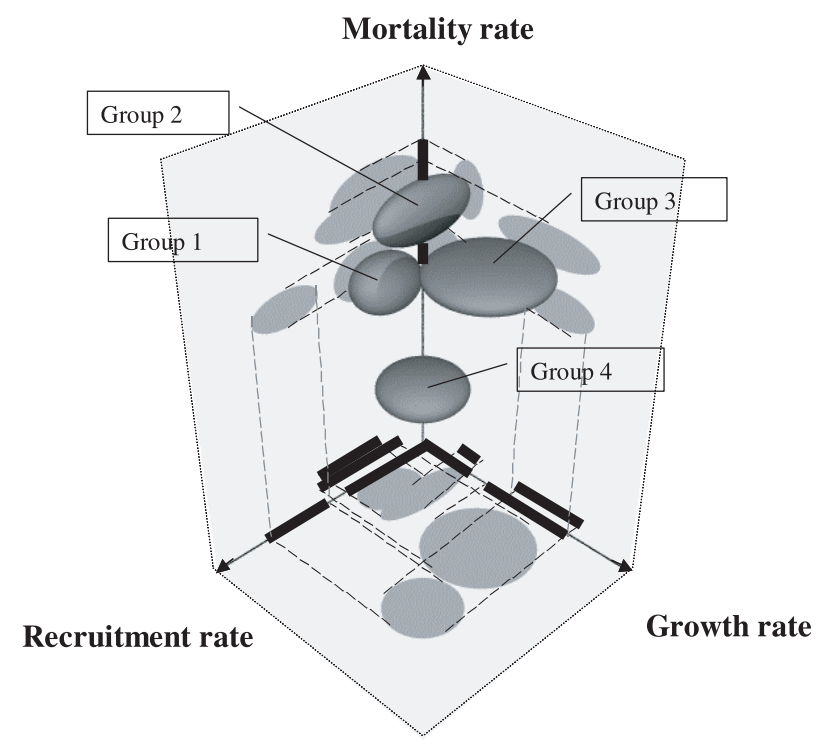

Figure 2. Illustration of the "ecological data-driven" grouping strategy. Four groups were built using cluster analysis on dynamics and morphological variables (see Tab. I). The projection on the three axes shows that the groups are poorly discriminated from the viewpoints of growth (two groups left), mortality (between one and two groups) and recruitment (two groups). When modelling those components for inclusion into dynamics models, the variability of the response will not be optimally taken into account.

"functional groups" sensu [29]. As a consequence, each species belongs to a given group and only one throughout its life-span. The groups are most often ecologically meaningful (Fig. 4 and later in text). In the second case, researchers creating dynamic process groups make no assumption about the existence of response or functional groups. To model the forest dynamics, they build separate classifications with respect to each dynamic process.

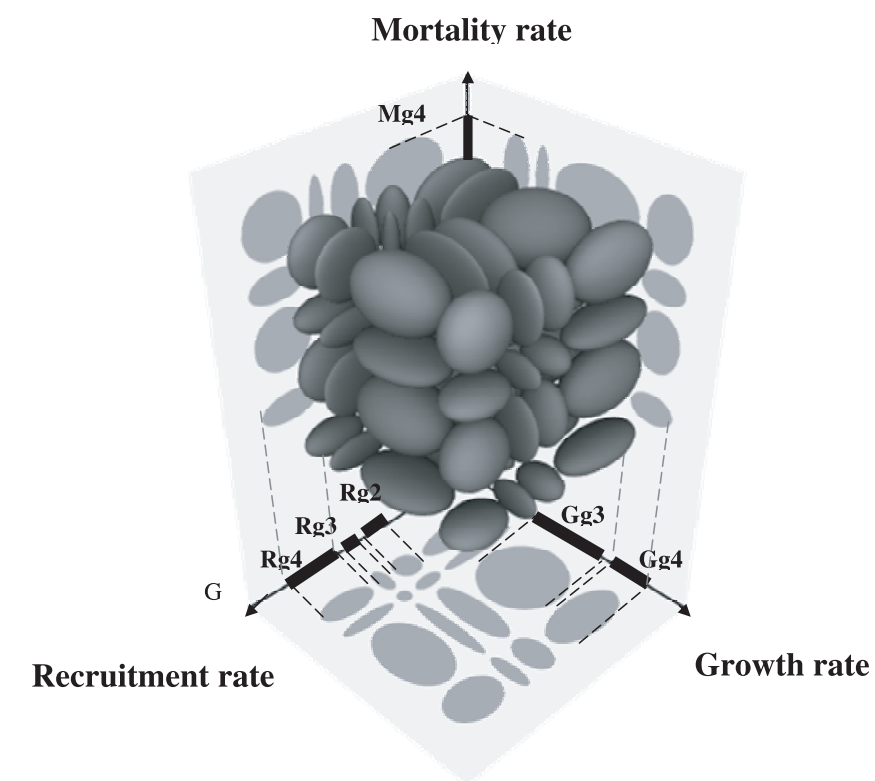

Figure 3. Illustration of the "dynamic process" grouping strategy. Species groups were built, using models describing growth (groups $\mathrm{Gg} 1$ to $\mathrm{Gg} 4$ ), mortality (groups Mg1 to Mg4) and recruitment (groups Rg1 to Rg4) separately. The combination of the $4 \times 4 \times 4$ sub-models allows the potential description of 64 groups of species (all the combinations do not necessarily exist) with the same quantity of parameters as in the strategy illustrated on Figure 2.

As this latter strategy (that will be named hereafter the "dynamic process" strategy) is the key concept of this paper, we shall clarify its implications. Each species needs to be assigned to three different groups for its complete dynamic behaviour to be described (Fig. 3). There are groups of species for growth, recruitment, and mortality. As a consequence, a species can shift from one group to another according to its lifestage, and the compared behaviour between two species differs

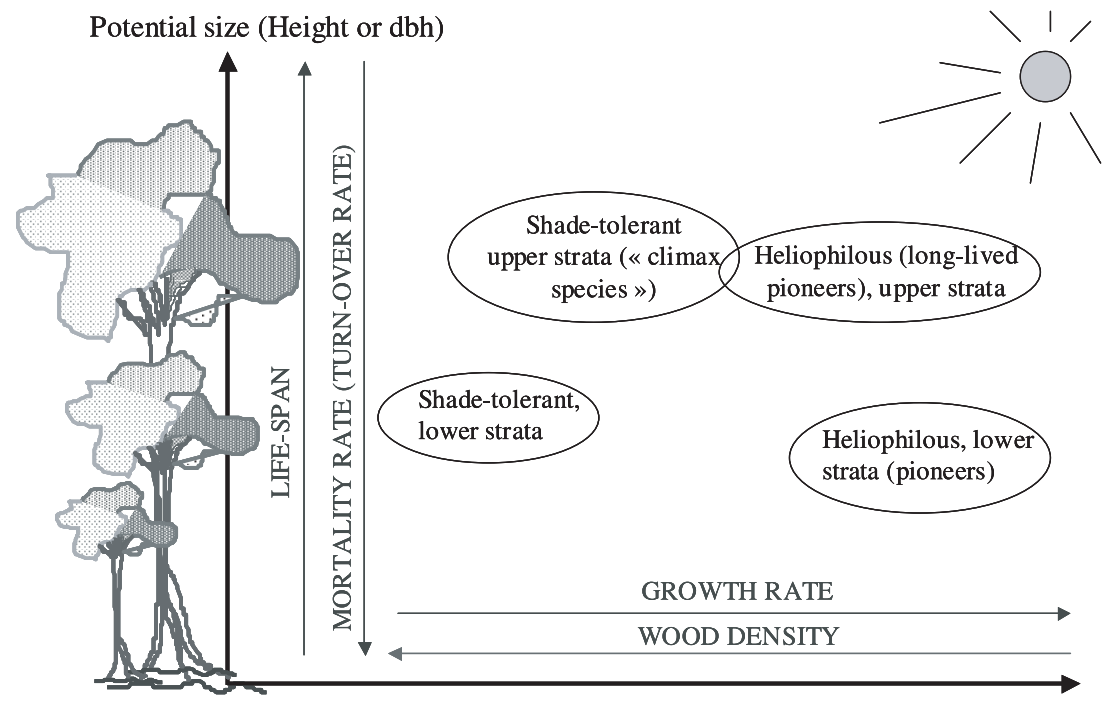

Light requirements, at least in young stages
Figure 4. General grouping scheme appearing in most of the studies on forest dynamics. The criteria most currently used to classify species are those appearing along the two axes. Classifications are generally obtained from one or two of those parameters. 
according to the life-stage. For instance, two species can belong to the same growth group and belong to separate mortality or recruitment groups. This strategy potentially allows describing a continuum of behaviours in the forest.

\section{PROPERTIES OF THE CHARACTERS USED TO DEFINE GROUPS}

Two properties emerging from the literature on species classifications for tropical forests help to understand the forthcoming results and to choose an adequate clustering strategy. Henceforth, we shall refer to these properties as the preliminaries. The first property deals with the dependence between tree characters used for species grouping, the second property with the intra-specific variability of these characters.

\subsection{Dependence between the characters}

Physiological, morphological and dynamic characters used to group species are not necessarily independent. Two sets of characters can however be considered as globally independent (Fig. 4). The first set of characters ( $y$-axis, Fig. 4) collates potential size, life span and mortality rate. The second set ( $x$-axis) collates growth rate and wood density. The independence between potential size and growth rate was already suggested by earlier works (e.g. [68]). Mortality rate here mainly concerns treefall, since standing death appears to be negatively correlated with the growth rate $[13,28,62]$. The negative correlation between maximum height and the mortality rate was frequently noticed [40, 41, 43, 68]. As an alternative to the mortality rate, some authors use the turn-over rate [68], which would suggest that high mortality rates are associated with high recruitment rates. Information regarding mortality, and more acutely, recruitment is generally scarce or incomplete. However, it is generally recognised that pioneer species are characterized by a high turnover rate due to both high mortality and high recruitment while non-pioneer species have a low turn-over rate (Tab. IV). [40] also found a decline, although not significant, in mortality rate from early to late successional species. Ecological groups can therefore be ordered according to an increasing turn-over rate as follows: pioneer species (and/or shade-intolerant species $) \approx$ understorey species $>$ canopy species $>$ emergent species. An illustration of such a trend between recruitment rates and ecological groups is given by [46]. However the correlation between mortality and recruitment rates was not confirmed by other studies [70, 71]. This could mean that our scheme of Figure 4 should be three-dimensional rather than two-dimensional, with the third axis representing recruitment, but it could result from the particular behaviour of pioneers: high rates do not occur at the same time, nor at the same place, while they do in understorey shade-tolerant species. Depending on the size of the stands considered and on their past disturbance history, links between recruitment and mortality rates will or will not appear.

Ecological groups of species can be located in the twodimensional space defined by Figure 4. Regarding the $x$-axis, pioneer species (and/or shade-intolerant species) generally show a faster growth rate than non-pioneers, with the exception of some emergent species (Tab. IV, see also [40]). Conversely, growth rate of non-pioneer species usually increases with the maximum height at maturity of the species. Ecological groups can therefore be ordered according to their decreasing growth rate in the following way [26, 33, 64]: pioneer species (and/or shade-intolerant species) $\approx$ emergent species $>$ canopy species $>$ understorey species (Tab. IV).

Let us finally note that, as a combined product of growth, mortality and recruitment, tree diameter distributions have often been suggested as characteristic of ecological groups, and used to classify species: shade-intolerant species usually exhibit distributions with a paucity of small stems whereas shade-tolerant species have a typical reversed-J curve [18, 39, 60, 61].

The schematic view that emerges from what precedes is that shade-intolerant species grow more quickly and die more frequently than shade-tolerant species that are characterised by low growth and low mortality; this being moderated by tree stature. Convergent examples are observed in temperate forests $[5,34]$. It has been proposed that shade-tolerance or intolerance is the result of trade-offs between high growth under high-light conditions and high survival under low-light conditions $[8,20-$ $22,35]$.

\subsection{Intra-specific variability of the characters}

In tropical forests, the variability of tree characters is generally high. Part of this variability is due to the genetic variability of the species; the remaining part results from the confounding effects of environment. As a consequence, a character can have a wide range of values even when restricting it to a species or a group of species with similar ecological behaviour. Examples can be found in $[27,40]$ for diameter increments and in [20] for mortality rates.

Species growth rate is usually estimated through a mean increment value irrespective of tree size [40, 41, 46, 65], although growth rate may $[14,17,20,26,32,53,66]$ or may not $[43,48]$ be correlated with tree size [50]. Moreover, species performance measured through growth rates is usually the average response of trees in a range of micro-environments. Exogenous factors can greatly modify the dynamics of species [37, 52]. Most tree species, for example, will grow faster after logging or thinning [33]. Vanclay [70] showed how inefficient were average growth rates for recognizing increment patterns, unless adjusted for tree size, site quality and competition.

There is, therefore, an inherent problem with attempts to characterise a given tree species with a single overall growth rate. This should be done after factoring out size and environmental factors either:

- by estimating maximum growth rates (or a quantile) rather than average ones (see e.g. [14]), because they are expected to express the species intrinsic growth potential without limiting factors. Generally, the range amongst species between the lowest and highest values is larger for maximum growth rates than for average rates [41, 49], or

- by using the residuals of models predicting growth from actual size with environmental factors taken as independent variables (Tab. II).

Note that the difficulties described for growth rate are even greater for mortality [66] and recruitment rates. Growth is a 
Table IV. Growth, mortality and recruitment (when available) characteristics of ecological groups, as found in literature.

\begin{tabular}{|c|c|c|c|c|c|c|c|c|}
\hline \multirow[t]{2}{*}{ Species groupings } & \multirow[t]{2}{*}{$\begin{array}{l}\text { No. of } \\
\text { species }\end{array}$} & \multirow[t]{2}{*}{$\begin{array}{l}\text { Min. } \\
\text { size }\end{array}$} & \multicolumn{2}{|c|}{$\begin{array}{c}\text { Max dbh annual } \\
\text { increment }\left(\mathrm{mm} \mathrm{yr}^{-1}\right)\end{array}$} & \multirow{2}{*}{$\begin{array}{c}\text { Mortality } \\
\text { rate } \\
\left(\% \mathrm{yr}^{-1}\right)\end{array}$} & \multirow{2}{*}{$\begin{array}{c}\text { Recruitment } \\
\text { rate } \\
\left(\% \mathrm{yr}^{-1}\right)\end{array}$} & \multirow[t]{2}{*}{$\begin{array}{l}\text { Forest type } \\
\text { and location }\end{array}$} & \multirow[t]{2}{*}{ Ref. } \\
\hline & & & Range & $\begin{array}{l}\text { Median } \\
\text { or mean }\end{array}$ & & & & \\
\hline Shade-intolerant sub-canopy and canopy sp. ${ }^{a}$ & 8 & $\geq 10$ & $6.7-14.6$ & 12.0 & & & La Selva & [46] \\
\hline Shade-tolerant sub-canopy and canopy sp. & 18 & $\mathrm{~cm}$ & $2.6-11.1$ & 5.6 & & & Biological Station & \\
\hline Understorey and shade-tolerant subcanopy sp. & 19 & $\mathrm{dbh}$ & $1.0-2.8$ & 1.7 & & & Costa Rica & \\
\hline Short-lived and long-lived pioneer sp. & 5 & $\geq 10$ & $5.5-13.5$ & 9.8 & & & Bukit Lagong Forest & [49] \\
\hline Emergent sp. & 3 & $\mathrm{~cm}$ & $9.3-14.3$ & 10.1 & & & Reserve, Hill & \\
\hline Main canopy sp. & 9 & dbh & $1.5-11.8$ & 6.6 & & & Dipterocarp Forest & \\
\hline Understorey sp. & 7 & & $0.9-5.1$ & 3.3 & & & Peninsular Malysia & \\
\hline Short-lived and long-lived (1l) pioneer sp. & 4 & $\geq 10$ & $3.2-6.8$ & 7.5 & 3.29 (11) & & Sungei Menyala & [48] \\
\hline Emergent sp. & 4 & $\mathrm{~cm}$ & $7.5-14.6$ & 9.6 & 1.43 & & Reserve, Lowland & [49] \\
\hline Main canopy sp. & 7 & dbh & $2.0-6.9$ & 5.6 & 1.82 & & Dipterocarp Forest & \\
\hline Understorey sp. & 9 & & $1.9-6.9$ & 4.0 & 2.58 & & Peninsular Malysia & \\
\hline Small pioneer & & $\geq 30$ & & 4.25 & 9.06 & 6.72 & Moist semi- & {$[65]$} \\
\hline Large pioneer & & $\mathrm{cm}$ & & 4.25 & 3.17 & 3.18 & deciduous & \\
\hline Shade intolerant & & gbh & & 1.86 & 1.65 & 1.58 & forest & \\
\hline Shade tolerant (canopy) & & & & 1.24 & 1.10 & 1.03 & Kade, Ghana & \\
\hline Shade-tolerant (understorey) & & & & 0.62 & 2.39 & 1.81 & & \\
\hline Canopy sp. & 5 & $\geq 10$ & $5.0-16.3$ & 5.1 & 3.2 & & Yasuni & [41] \\
\hline Large-stemmed mid canopy sp. (age $\leq 350 \mathrm{yr}$ ) & 9 & $\mathrm{~cm}$ & $1.2-6.4$ & 4.4 & 2.9 & & National Park & \\
\hline Small-stemmed canopy sp. (200 yr max age) & 7 & $\mathrm{dbh}$ & $2.4-7.0$ & 3.1 & 2.1 & & Ecuador & \\
\hline Understorey sp. (200 yr max age) & & & & & 2.0 & & & \\
\hline Canopy sp. & & $\geq 2.5$ & & & $14^{\mathrm{b}}$ & & Barro Colorado & [43] \\
\hline Mid canopy sp. & & $\mathrm{cm}$ & & & $31^{\mathrm{b}}$ & & Island & \\
\hline Understorey sp. & & $\mathrm{dbh}$ & & & $26^{\mathrm{b}}$ & & Panama & \\
\hline Emergent and upper canopy sp. & 10 & $\geq 10$ & $0-20$ & & & & Hill evergreen & [53] \\
\hline Lower canopy sp. & 9 & $\mathrm{~cm}$ & $0-10$ & & & & forest & \\
\hline Understorey sp. & 5 & gbh & $0-2.5$ & & & & Kerala, India & \\
\hline
\end{tabular}

a Higher diameter increments were recorded for pioneer species $\geq 10 \mathrm{~cm}$ dbh in Panama (73.4 $\mathrm{mm} \mathrm{yr}^{-1}$ for Ochroma pyramidale at Barro Colorado Island, [17]) and in French Guiana (80.0 mm yr ${ }^{-1}$ for Cecropia obtusa at Paracou, [32]).

$\mathrm{b}$ Mortality rate calculated for a 10 years period.

more or less constant process whereas death and recruitment are instantaneous, randomly distributed and highly variable in time and space.

\section{CONGRUENCY BETWEEN CLASSIFICATIONS}

We reviewed how different classifications compare, and summarised the results in Table V. As expected from Figure 4, there are links between the potential size, life-span, mortality rates and turn-over rates of trees on the one hand and between shade tolerance/intolerance in the juvenile stages, growth rates and wood density on the other hand. By using one or other of these variables, species can be classified into a limited number of groups, logically positioned along the axes of Figure 4 as aggregates or refined versions of the four generic groups represented within the figure. This scheme is reminiscent of several found in the literature: the four groups of [49] based on maximum height and the dichotomy pioneer/non pioneer, the five groups of [24] based on maximum dbh and dynamic variables, or the 13 plant-functional types of [40], based on maximum height and wood-density, more or less continuously dispersed across the paraboloid represented by our generic groups.

A certain degree of congruency can exist between classifications based on correlated variables. [68], for instance, produced a two-way classification of tree species based on the two sets of variables shown in Figure 4 and showed its coherence 
Table V. Results of congruency analysis between species classifications.

\begin{tabular}{|c|c|}
\hline Classifications & Ecological subjective groups \\
\hline $\begin{array}{l}\text { Ecological subjective } \\
\text { groups }\end{array}$ & $\begin{array}{l}\text { Cross-comparisons between groups of } \\
\text { [15], based on height-diameter curves } \\
\text { characteristics, edaphic preferences, spa- } \\
\text { tial pattern, dispersal syndrome, popula- } \\
\text { tion density. } \\
\text { No convergence between any of the clas- } \\
\text { sifications. }\end{array}$ \\
\hline $\begin{array}{l}\text { Ecological data-driven } \\
\text { groups (see Tab. I) }\end{array}$ & $\begin{array}{l}\text { Groups of [1] and [23] vs. groups based } \\
\text { on shade-tolerance, dispersal syndrome, } \\
\text { seed size and wood density. } \\
\text { Global tendencies: pioneer and heliophi- } \\
\text { lous species tend to grow faster, to have } \\
\text { smaller seeds and lighter wood than } \\
\text { shade-tolerant species. } \\
\text { Low congruency: the species of any eco- } \\
\text { logical group are found in all dynamic } \\
\text { groups. }\end{array}$ \\
\hline
\end{tabular}

Dynamic process groups (see Tabs. II and III)
Growth groups of [70] vs. groups based on shade-tolerance, growth groups and mortality groups [71] vs. size reached at maturity, and taxonomy.

Low congruency: pioneers and gap-colonizers encompass several growth groups, the same growth group can include shade-tolerant and light-demanding species. Size at maturity weakly related to growth groups, while there is a link with mortality groups. No relationship with taxonomy.

Growth groups of [31] vs. groups of [15] based on parameters of height/diameter curves and interpreted in terms of light needs.

Some agreements for extreme categories: growth patterns of the small shade-tolerant species are completely different from those of the canopy light demanding species.

Low congruency: no particular growth group match with any of the other six ecological groups.
Growth groups of [33] vs. groups of [23].

Low congruency: close agreement only for the pioneer group and one growth group. The other Favrichon's groups include at least seven different growth groups, and most of the growth patterns gather species belonging to two or three ecological data-driven groups.
Cross-comparisons between the growth, mortality and recruitment groups of [70, 71, 72].

No congruency between the growth and neither the mortality nor the recruitment groups. No congruency between the mortality and the recruitment groups. No congruency between the two levels of recruitment groups (probability of recruitment and amount of recruitment, see Table III).

Cross-comparisons between the growth, mortality and recruitment groups of [57]. Same results as for Vanclay above. with Shugart's two-way classification of trees on their gap requirement and propensity to form gaps when they die [62]. This result can be explained by our first preliminary property (as defined in the third section) because a "propensity to create gaps" can be related to maximum height ( $y$-axis) and "gap requirement" can be related to growth rate ( $x$-axis). Another example is provided by [30], who compared four different classifications of Australian tree species based on shade-tolerance or successional status ("subjective classification"), seed persistence + light and growth response, morphological + life-history + phenological traits and dynamic variables. Their results are consistent with the first preliminary property. In their "dynamic data set", about half the variables are related to size structure and tree mean size through dbh, while the other half deals with mortality, recruitment and growth of adults and juveniles: the two axes of Figure 4 are thus taken into account. In the "morphological data set", variables are linked to stature, leaf morphology and reproductive/dispersal characters, that is to say mostly variables linked to the $y$-axis. The subjective classification (pioneer, early, mid and late successional species) is a simplified version of the generic groups presented in Figure 4 and could be positioned along the $x$-axis. As expected, some coherence could be found between the dynamic and subjective classifications (both taking the $x$-axis into account) while no link could be found between the morphological and subjective classification. The "little coherence" found to occur between the dynamic and morphological classifications is probably explained by the variables linked to the $y$-axis in both of them. 
On the contrary, no congruency between classifications will be found if they are based on independent sets of characters. For instance [15] made five independent classifications of a set of French Guiana species, and observed no convergence between them. The first preliminary property may also explain why the classification of [15] based on height and diameter variables has almost nothing to do with the classification of [31] based on diameter growth. Similarly, the independence between variables can explain why the growth and mortality groups of $[70,71]$ are not coherent, or the inability of maximum size to indicate increment patterns [70].

Overall, congruency turned out to be limited. A somewhat disappointing but not surprising finding. It seems that the best results for a worldwide classification into functional types, in terms of congruence or convergence, were obtained when considering a full range of life forms (sensu [58]) in a given ecosystem (see, e.g., [74]), or limited types between contrasted environments [44]. The tropical trees that we examined here form an assemblage within a single life form. This work points to a need to consider a much wider range of variables than has been done to date, like those available in databases of taxa characteristics.

\section{SELECTED CLUSTERING STRATEGY FOR MODELLING TROPICAL FOREST DYNAMICS}

Ecological strategies show a major drawback: once the groups are obtained, they are used to calibrate the growth, mortality and recruitment sub-models that are part of the overall forest dynamics models (see Tab. I, and Fig. 2 for an illustration of this strategy). As previously mentioned, the important and implicit assumption, in this case, is that the so-defined dynamic groups should behave homogeneously in all the dynamic components: two species that are in the same growth group are in the same mortality or recruitment group. This would indicate a certain degree of redundancy. The frequently observed independence between variables helps to understand that this is unrealistic. Subjective groups add two supplementary problems, compared to data driven ones: (i) they are built from biological characters that are not directly linked with growth, mortality and recruitment, and (ii) the intra-specific variability of those characters is high. These two points jointly hinder the calibration of growth, mortality and recruitment models with low-variance parameters estimates.

As a consequence, we argue that the best strategy is to build dynamic process groups. We hereafter discuss the pros and cons of this strategy.

Contrary to the other strategies, the dynamic process strategy is bound to a model. A drawback of this strategy is that the ecological meaning of the groups may not be straightforward. The priority in that strategy is not to build ecologically meaningful groups to be subsequently used in a model, but rather to use the model to build the groups and afterwards, a possible ecological meaning is addressed. Moreover, the direct use of dynamic variables to group species leads to a focus more on phenomena than on mechanisms, with a gain in predictive power being accompanied by a loss of explanatory capability.
It also needs time-series data from permanent sample plots, which are few in the tropics although expanding.

Nevertheless, the dynamic process strategy can address, to a certain extent, the possible lack of ecological meaning of the groups. Growth groups, mortality groups or recruitment groups do not necessarily hold an ecological meaning [70-72]. Crossing them will usually lead to a great number of small groups corresponding to detailed behaviours (growth $\times$ mortality $\times$ recruitment), with a given set of sub-models. There is no reason why those small groups could not be clustered a posteriori in order to match with broader "ecological" classifications which are more interpretable by ecologists. An advantage is that the clustering can be done in various ways, according to the questions asked by the researchers and without any necessity to re-build the set of dynamics sub-models. For example, consider species groups defined on the basis of $\delta^{15} \mathrm{~N}$ and leaf $\mathrm{N}$ content by ecophysiologists (e.g. [59]) wishing to predict the long-term consequences of logging operations on the ability of the stand to capture different $\mathrm{N}$ sources. They need to compare the relative importance of their groups at the beginning of a simulation, before disturbance, and to predict them several years after. Instead of calibrating growth, mortality and recruitment sub-models adapted to each of their $\mathrm{N}$ groups, they could use the small groups initially defined for dynamic modelling purposes and of their associated sub-models, clustering them into the $\mathrm{N}$ groups at each step of the simulation. The same operation could be done with a pioneer/mid-tolerant/tolerant classification, a $\delta^{13} \mathrm{C}$ classification or a commercial/non-commercial one, depending on the objective. In particular, this strategy permits the investigation of the potential effects of disturbances on stand functions, through the modification of its diversity, which is a particularly important issue [63]. The ecological datadriven strategy would not allow the same flexibility, as it would be too coarse, not providing enough groups to allow agglomeration into another classification.

Second, the underlying growth models that are used in the dynamic process strategy can elucidate fundamental principles of interest to ecologists. In fact, depending on the way they are built, they can account for confounding factors such as diameter, local competition, disturbance history and position in the canopy, thus giving direct access to some kind of intrinsic growth trait characterizing each species.

It has been argued that the dynamic process strategy tends to produce too many groups [29]. However Tables II and III show that the ecological data-driven strategy can lead to as many groups and sometimes more than the dynamic process strategy. Moreover, the number of parameters is more essential than the number of groups. Changing from the ecological datadriven strategy, which generally gives a small number of groups, to the dynamic process strategy, which gives a greater number of groups, can be strictly equivalent in terms of number of estimated parameters in a model of forest dynamics. Consider for example that a forest has been simplified into four ecological data-driven groups, and a matrix model has been built to predict their evolution after disturbance: growth, mortality and recruitment sub-models have been calibrated for each of the four groups of species, in order to obtain four sub-matrices. Using the dynamic process strategy to obtain four growth groups, four mortality groups and four recruitment groups independent of each other will require the same number of parameters 
to be estimated [57]. But decoupling the different components potentially creates the identification of $4 \times 4 \times 4=64$ types of species behaviours (see Figs. 2 and 3 for a simplified illustration). This allows the global dynamics model to incorporate more of the subtlety of potential reactions to disturbances increasing the model's power to assess possible effect on floristic diversity. Such a result could not be obtained by the simple refinement of ecological data-driven groups, as dividing four groups into 64 groups would lead to data sets too small to calibrate the sub-models.

Another consequence of the dynamic process strategy is that it can take into account the high intra-specific variability of dynamics behaviours during the life-cycle of plants. Any one of the species studied is likely to be allocated to different groups according to the life stage reached by its individuals. This is coherent with the theoretical view of [50] and field observations $[4,14]$. Ideally, the whole life cycle and particularly the little-studied period from seeds to trees $\geq 10 \mathrm{~cm}$ dbh should be split into several stages, each stage being the object of an independent classification.

Finally, the dynamic process strategy also contributes in reducing the variance in the parameter fitting, since it works separately on each of the components modelled, and rebuilds different groups of species according to the process under focus. As a consequence, the dynamic process strategy should be preferred in grouping species for modelling purposes.

\section{CONCLUSION}

Little evidence of the existence of universal groups of tropical woody species can be found in the published work. Among the tests of functional classifications suggested by [29] in order to check the existence of such groups, we mainly addressed congruency and concluded that it was, at best, limited. In the absence of clearly identified universal groups of species within tropical forests, we believe that the best strategy for simplifying species diversity, in order to build efficient dynamics models to predict the changes in forest structure after disturbance, is to rely on the "dynamic process" strategy.

However, an important prospect is the potentiality to extrapolate an existing species classification to other forests, because of the limited number of permanent plots surveyed across the tropical world. This could be achieved by identifying traits (other than those currently found in most studies) that could be used as proxies of dynamics variables. The existing permanent sample plots are ideal places to seek these proxies. Proxies for growth, proxies for mortality, and proxies for recruitment should be investigated to be consistent with the dynamic process strategy. This would allow us to use this grouping strategy with easily measurable criteria such as physiological or morphological characters.

\footnotetext{
Acknowledgements: This work is issued from the EuroWorkshop "Functional Groupings of Tropical Trees: Simplifying Species Complexity as an Aid to Understanding Tropical Forests" funded by the High-Level Scientific Conferences Human Potential programme of the European Commission and held in Edinburgh in Dec. 2001. The authors are grateful to Guillaume Cornu, who gave precious help for realising Figures 2 and 3 illustrating the text. We also thank two anonymous reviewers for their helpful remarks.
}

\section{REFERENCES}

[1] Alder D., The Preliminary Development of the CAFOGROM Forest Growth Model, Internal consultancy report, ODA/CPATU Silviculture Research Project, Belém, Brazil, 1994.

[2] Alder D., Silva J.N.M., An empirical cohort model for management of Terra Firme forests in the Brazilian Amazon, For. Ecol. Manage. 130 (2000) 141-157.

[3] Alder D., Synnott T.J., Permanent Sample Plot Techniques for Mixed Tropical Forest, Tropical Forestry Papers 25, Oxford Forestry Institute, Department of Plant Sciences, University of Oxford, Oxford, 1992.

[4] Alvarez-Buylla E.R., Martinez-Ramos M., Demography and allometry of Cecropia obtusifolia, a neotropical pioneer tree, an evaluation of the climax-pioneer paradigm for tropical rain forests, J. Ecol. 80 (1992) 275-290.

[5] Assmann E., The Principles of Forest Yield Study, Pergamon Press, Oxford, UK, 1970.

[6] Atta-Boateng J., Moser J.W., A method for classifying commercial tree species of an uneven-aged mixed species tropical forest for growth and yield model construction, For. Ecol. Manage. 104 (1998) 89-99.

[7] Aubréville A.M.A., La forêt coloniale: les forêts de l'Afrique Occidentale Française, Société d'Éditions Géographiques, Paris, 1938.

[8] Bazzaz F.A., Dynamics of wet tropical forests and their species strategies, in: Medina E., Mooney M.A., Vásquez-Yánes C. (Eds.), Physiological ecology of plants of the wet tropics: proceedings of an international symposium held in Oxatepec and Los Tuxtlas, Mexico, June 29 to July 6, 1983, W. Junk, The Hague, 1984, pp. 233-243.

[9] Bazzaz F.A., Pickett S.T.A., Physiological ecology of tropical succession: a comparative review, Annu. Rev. Ecol. Syst. 11 (1980) 287-310.

[10] Boscolo M., Buongiorno J., Condit R., A model to predict biomass recovery and economic potential of a neotropical forest, in: Panayotou T. (Ed.), Environment for Growth: Environmental Management for Sustainability and Competitiveness in Central America, Harvard Studies in International Development, Harvard University Press, Cambridge, Massachusetts, 2001, p. 608.

[11] Bossel H., Krieger H., Simulation model of natural tropical forest dynamics, Ecol. Model. 59 (1991) 37-71.

[12] Budowski G., The distinction between old secondary and climax species in tropical central American lowland forests, Trop. Ecol. 11 (1970) 44-48.

[13] Carey E.V., Brown S., Gillespie A.J.R., Lugo A.E., Tree mortality in mature lowland tropical moist and tropical lower montane moist forests of Venezuela, Biotropica 26 (1994) 255-265.

[14] Clark D.A., Clark D.B., Assessing the growth of tropical rain forest trees: issues for forest modeling and management, Ecol. Appl. 9 (1999) 981-997.

[15] Collinet F., Essai de regroupements des principales espèces structurantes d'une forêt dense humide d'après l'analyse de leur répartition spatiale, Thèse de doctorat, Université Claude Bernard-Lyon I, Lyon, 1997.

[16] Condit R., Research in large, long-term tropical forest plots, Trends Ecol. Evol. 10 (1995) 18-22.

[17] Condit R., Hubbell S.P., Foster R.B., Mortality and growth of a commercial hardwood "el cativo", Prioria copaifera, in Panama, For. Ecol. Manage. 62 (1993) 107-122.

[18] Condit R., Sukumar R., Hubbell S.P., Foster R.B., Predicting population trends from size distributions: a direct test in a tropical tree community, Am. Nat. 152 (1998) 495-509.

[19] Crow T.R., A rainforest chronicle: a 30-year record of change in structure and composition at El Verde, Puerto Rico, Biotropica 12 (1980) 42-55. 
[20] Davies S.J., Tree mortality and growth in 11 sympatric Macaranga species in Borneo, Ecology 82 (2001) 920-932.

[21] Denslow J.S., Gap partitioning among tropical rainforest trees, Biotropica 12 (1980) 47-55.

[22] Denslow J.S., Tropical rainforest gaps and tree species diversity, Annu. Rev. Ecol. Syst. 18 (1987) 431-451.

[23] Favrichon V., Classification des espèces arborées en groupes fonctionnels en vue de la réalisation d'un modèle de dynamique de peuplement en forêt guyanaise, Rev. Écol. (Terre et Vie) 49 (1994) 379-403.

[24] Favrichon V., Modèle matriciel déterministe en temps discret. Application à l'étude de la dynamique d'un peuplement forestier tropical humide (Guyane française), Thèse de doctorat, Université Claude Bernard-Lyon I, Lyon, 1995.

[25] Favrichon V., Gourlet-Fleury S., Dessard H., Bar-Hen A., Parcelles permanentes de recherche en forêt dense tropicale humide. Éléments pour une méthodologie d'analyse de données, Série FORAFRI, Vol. 14, CIRAD, Montpellier, 1998.

[26] Felfili J.M., Growth, recruitment and mortality in the Gama gallery forest in central Brazil over 6 year period (1985-1991), J. Trop. Ecol. 11 (1995) 67-83.

[27] Finegan B., Camacho M., Zamora N., Diameter increment patterns among 106 tree species in a logged and silviculturally treated Costa Rican rain forest, For. Ecol. Manage. 121 (1999) 159-176.

[28] Franc A., Gourlet-Fleury S., Picard N., Introduction à la modélisation des forêts hétérogènes, ENGREF, Nancy, 1999.

[29] Gitay H., Noble I.R., What are functional types and how should we seek them? in: Smith T.M., Shugart H.H., Woodward F.I. (Eds.), Plant Functional Types: Their Relevance to Ecosystem Properties and Global Change, International Geosphere-Biosphere Programme, Vol. 1, Cambridge University Press, Cambridge, 1997, pp. 3-19.

[30] Gitay H., Noble I.R., Connell J.H., Deriving functional types for rain-forest trees, J. Veg. Sci. 10 (1999) 641-650.

[31] Gourlet-Fleury S., Modélisation individuelle spatialement explicite de la dynamique d'un peuplement de forêt dense tropicale humide (dispositif de Paracou, Guyane française), Thèse de doctorat, Université Claude Bernard-Lyon I, Lyon, 1997, 2 volumes.

[32] Gourlet-Fleury S., Dispositif sylvicole expérimental de Paracou (Guyane française): aperçus sur l'état et la dynamique des peuplements 13 ans après installation, rapport technique, Silvolab, Kourou, Guyane et Cirad-Forêt, Montpellier, 2000, 2 volumes.

[33] Gourlet-Fleury S., Houllier F., Modelling diameter increment in a lowland evergreen rain forest in French Guiana, For. Ecol. Manage. 131 (2000) 269-289.

[34] Harcombe P.A., Tree life tables: simple birth, growth and death data encapsulate life histories and ecological roles, Bioscience 37 (1987) 557-568.

[35] Hartshorn G.S., Neotropical forest dynamics, Biotropica 12 (1980) 23-30.

[36] Hladik A., Dynamique d'une forêt équatoriale africaine: mesures en temps réel et comparaison du potentiel de croissance des différentes espèces, Acta Oecol. Oecol. Gen. 3 (1982) 373-392.

[37] Hubbell S.P., Foster R.B., La estructura espacial en gran escala de un bosque neotropical, Rev. Biol. Trop. 35 (1987) 7-22.

[38] Huth A., Ditzer T., Long-term impacts of logging in a tropical rain forest - a simulation study, For. Ecol. Manage. 142 (2001) 33-51.

[39] Knight D.H., A phytosociological analysis of species-rich tropical forest on Barro Colorado Island, Panama, Ecol. Monogr. 45 (1975) 259-284.

[40] Köhler P., Ditzer T., Huth A., Concepts for the aggregation of tropical tree species into functional types and the application to Sabah's lowland rain forests, J. Trop. Ecol. 16 (2000) 591-602.
[41] Korning J., Balslev H., Growth rates and mortality patterns of tropical lowland tree species and the relation to forest structure in Amazonian Ecuador, J. Trop. Ecol. 10 (1994) 151-166.

[42] Lahoreau G., Picard N., Gourlet-Fleury S., Grouping species to model forest dynamics: a case study of a forest in the Central African Republic, Bois For. Trop. 271 (2002) 89-100.

[43] Lang G.E., Knight D.H., Tree growth, mortality, recruitment, and canopy gap formation during a 10 -year period in a tropical moist forest, Ecology 64 (1983) 1075-1080.

[44] Lavorel S., Garnier E., Predicting changes in community composition and ecosystem functioning from plant traits: revisiting the Holy Grail, Funct. Ecol. 16 (2002) 545-556.

[45] Lavorel S., McIntyre S., Landsberg J., Forbes T.D.A., Plant functional classifications: from general groups to specific groups based on response to disturbance, Trends Ecol. Evol. 12 (1997) 474-478.

[46] Lieberman D., Lieberman M., Hartshorn G., Peralta R., Growth rates and age-size relationships of tropical wet forest trees in Costa Rica, J. Trop. Ecol. 1 (1985) 97-109.

[47] Lortet J., Formation de groupes d'espèces homogènes pour la croissance dans la forêt dense tropicale humide d'Uppangala, Inde, Mémoire de DEA, Université Claude Bernard Lyon 1, Lyon, 1998.

[48] Manokaran N., Kochumen K.M., Recruitment, growth and mortality of tree species in a lowland dipterocarp forest in Peninsular Malaysia, J. Trop. Ecol. 3 (1987) 315-330.

[49] Manokaran N., Kochumen K.M., Tree growth in primary lowland and hill dipterocarp forests, J. Trop. For. Sci. 6 (1994) 332-345.

[50] Oldeman R.A.A., Van Dijk J., Diagnosis of the temperament of tropical rain forest trees, in: Gomez-Pompa A., Whitmore T.C., Hadley M. (Eds.), Rain Forest Regeneration and Management, UNESCO - Man and the Biosphere Series, Vol. 6, The Parthenon Publishing Group, Paris, 1991, pp. 21-63.

[51] Ong R., Kleine M., DIPSIM: A Dipterocarp Forest Growth Simulation Model for Sabah, FRC Research Papers 2, Forestry Department, Sabah, Malaysia, 1996.

[52] Pascal J.P., Pélissier R., Structure and floristic composition of a tropical evergreen forest in south-west India, J. Trop. Ecol. 12 (1996) 191-214.

[53] Pélissier R., Pascal J.P., Two-year tree growth patterns investigated from monthly girth records using dendrometer bands in a wet evergreen forest in India, J. Trop. Ecol. 16 (2000) 429-446.

[54] Phillips O.L., Gentry A.H., Increasing turnover through time in tropical forests, Science 263 (1994) 954-958.

[55] Phillips P.D., Yasman I., Brash T.E., van Gardingen P.R., Grouping tree species for analysis of forest data in Kalimantan (Indonesian Borneo), For. Ecol. Manage. 157 (2002) 205-216.

[56] Picard N., Franc A., Are ecological groups of species optimal for forest dynamics modelling? Ecol. Model. 163 (2003) 175-186.

[57] Picard N., Gourlet-Fleury S., Sist P., Using process-dependent groups of species to model the dynamics of a tropical rain-forest, in: Amaro A., Reed D., Soares P. (Eds.), Modelling Forest Systems, CAB International Publishing, Wallingford, 2003, pp. 237-248.

[58] Raunkiaer C., The Life-forms of Plants and Statistical Plant Geography, Oxford University Press, Oxford, 1934.

[59] Roggy J.C., Prévost M.F., Gourbiere F., Casabianca H., Garbaye J., Domenach A.M., Leaf natural ${ }^{15} \mathrm{~N}$ abundance and total $\mathrm{N}$ concentration as potential indicators of plant $\mathrm{N}$ nutrition in legumes and pioneer species in a rainforest of French Guiana, Ecologia 120 (1999) 171-182.

[60] Rollet B., Étude quantitative d'une forêt dense humide sempervirente de Guyane vénézuelienne, Thèse de doctorat, Université de Toulouse, Toulouse, 1969.

[61] Rollet B., L'architecture des forêts denses humides sempervirentes de plaine, CTFT, Nogent-sur-Marne, 1974. 
[62] Shugart H.H., A Theory of Forest Dynamics: The Ecological Implications of Forest Succession Models, Springer Verlag, New York, 1984.

[63] Silver W.L., Brown S., Lugo A.E., Effects of changes in biodiversity on ecosystem function in tropical forests, Conserv. Biol. 10 (1996) 17-24.

[64] Sist P., Nguyen-Thé N., Logging damage and the subsequent dynamics of a dipterocarp forest in East Kalimantan (1990-1996), For. Ecol. Manage. 165 (2002) 85-103.

[65] Swaine M.D., Population dynamics of moist tropical forest near Kade, Ghana, in: Puig H. (Ed.), Atelier sur l'aménagement et la conservation de l'écosystème forestier tropical humide, UNESCO, IUFRO, FAO, Paris, 1992, pp. 40-61.

[66] Swaine M.D., Hall J.B., Alexander I.J., Tree population dynamics at Kade, Ghana (1968-1982), J. Trop. Ecol. 3 (1987) 331-345.

[67] Swaine M.D., Whitmore T.C., On the definition of ecological species groups in tropical rain forests, Vegetatio 75 (1988) 81-86.

[68] Turner I.M., The Ecology of Trees in the Tropical Rain Forest, Cambridge Tropical Biology Series, Cambridge University Press, Cambridge, 2001.
[69] Van Steenis C.G.G.J., Rejuvenation as a factor for judging the status of vegetation types. The biological nomad theory, in: Study of Tropical Vegetation. Proceedings of the Kandy symposium on humid tropics vegetation, Kandy, Ceylon, 19-21 March 1956, UNESCO, Paris, 1956, pp. 212-215.

[70] Vanclay J.K., Aggregating tree species to develop diameter increment equations for tropical rainforests, For. Ecol. Manage. 42 (1991) 143-168.

[71] Vanclay J.K., Mortality functions for North Queensland rainforests, J. Trop. For. Sci. 4 (1991) 15-36.

[72] Vanclay J.K., Modelling regeneration and recruitment in a tropical moist forest, Can. J. For. Res. 22 (1992) 1235-1248.

[73] Wan Razali B.W.M., Development of a generalized forest growth and yield modelling system for mixed tropical forests of peninsular Malaysia, Ph.D. thesis, University of Washington, 1986.

[74] Westoby M., Leishman M., Categorizing plant species into functional types, in: Smith T.M., Shugart H.H., Woodward F.I. (Eds.), Plant Functional Types: Their Relevance to Ecosystem Properties and Global Change, IGBP Book Series, Vol. 1, Cambridge University Press, Cambridge, 1997, pp. 104-121. 